\title{
Effects of a preemptive alveolar recruitment strategy on arterial oxygenation during one-lung ventilation with different tidal volumes in patients with normal pulmonary function test
}

\author{
Jong Dal Jung ${ }^{1,2}$, Sang Hun Kim ${ }^{1,2}$, Byung Sik Yu ${ }^{1,2}$, and Hye Ji Kim ${ }^{2}$ \\ Department of Anesthesiology and Pain Medicine, ${ }^{1}$ Chosun University School of Medicine, ${ }^{2}$ Chosun University Hospital, Gwangju, \\ Korea
}

Background: Hypoxemia during one-lung ventilation (OLV) remains a major concern. The present study compared the effect of alveolar recruitment strategy (ARS) on arterial oxygenation during OLV at varying tidal volumes (Vt) with or without positive end-expiratory pressure (PEEP).

Methods: In total, 120 patients undergoing wedge resection by video assisted thoracostomy were randomized into four groups comprising 30 patients each: those administered a $10 \mathrm{ml} / \mathrm{kg}$ tidal volume with or without preemptive ARS (Group $\mathrm{H}$ and Group H-ARS, respectively) and those administered a $6 \mathrm{ml} / \mathrm{kg}$ tidal volume and a $8 \mathrm{cmH}_{2} \mathrm{O}$ PEEP with or without preemptive ARS (Group L and Group L-ARS, respectively). ARS was performed using pressure-controlled ventilation with a $40 \mathrm{cmH}_{2} \mathrm{O}$ plateau airway pressure and a $15 \mathrm{cmH}_{2} \mathrm{O}$ PEEP for at least 10 breaths until OLV began.

Results: Preemptive ARS significantly improved the $\mathrm{PaO}_{2} / \mathrm{FiO}_{2}$ ratio compared to the groups that did not receive ARS $(\mathrm{P}<0.05)$. The $\mathrm{H}$-ARS group showed a highest $\mathrm{PaO}_{2} / \mathrm{FiO}_{2}$ ratio during OLV, the L-ARS and $\mathrm{H}$ groups showed similarly improved arterial oxygenation, which was significantly higher than in group $\mathrm{L}(\mathrm{P}<0.05)$. The plateau airway pressure in group H-ARS was significantly higher than in group L-ARS $(\mathrm{P}<0.05)$.

Conclusions: Preemptive ARS can improve arterial oxygenation during OLV. Furthermore, a $6 \mathrm{ml} / \mathrm{kg}$ tidal volume combined with $8 \mathrm{cmH}_{2} \mathrm{O}$ PEEP after preemptive ARS may reduce the risk of pulmonary injury caused by high tidal volume during one-lung ventilation in patients with normal pulmonary function. (Korean J Anesthesiol 2014; 67: 96-102)

Key Words: Alveolar recruitment, One-lung ventilation, Oxygenation, PEEP, Preemptive, Tidal volume.

\footnotetext{
Received: January 20, 2014. Revised: 1st, March 6, 2014; 2nd, March 19, 2014. Accepted: May 25, 2014.

Corresponding author: Sang Hun Kim, M.D., Ph.D., Department of Anesthesiology and Pain Medicine, Chosun University School of Medicine, 309, Pilmun-daero, Dong-gu, Gwangju 501-759, Korea. Tel: 82-62-220-3223, Fax: 82-62-223-2333, E-mail: ksh3223@Chosun.ac.kr

(c) This is an open-access article distributed under the terms of the Creative Commons Attribution Non-Commercial License (http:// creativecommons.org/licenses/by-nc/3.0/), which permits unrestricted non-commercial use, distribution, and reproduction in any medium, provided the original work is properly cited.
} 


\section{Introduction}

During thoracic surgery, one-lung ventilation (OLV) is essential to isolate the targeted lung [1]. However, there is a $4-10 \%$ risk of hypoxemia during OLV [1-3], and preventing this risk remains a major concern. Ideally, the tidal volume should maintain adequate oxygenation and prevent hypoxemia during OLV [4], but the ideal tidal volume is debatable. Some authors recommend using the conventional tidal volume (10-12 $\mathrm{ml} / \mathrm{kg}$ ) for two-lung ventilation (TLV) to prevent atelectasis that can occur below $<8 \mathrm{ml} / \mathrm{kg}$ [4,5]. However, others state that the conventional tidal volume may cause pulmonary injury, and they recommend ventilating at a $5-6 \mathrm{ml} / \mathrm{kg}$ tidal volume, along with a sufficient positive end-expiratory pressure (PEEP) to reduce or prevent lung injury and arterial hypoxemia [6-9].

Arterial hypoxemia during OLV may be caused by atelectasis within the dependent lung due to the lateral decubitus position and by anesthesia, which reduces the functional residual capacity [10-12]. The alveolar recruitment strategy (ARS), using high inspiratory pressure (recruitment maneuver) followed by external PEEP to keep the recruited alveoli open, has been investigated as a way to prevent hypoxemia during OLV, though various methodologies have been performed [13-16]. Several reports investigate preemptive ARS performed on both lungs before beginning OLV $[13,14]$; though arterial oxygenation did improve during OLV using a $6 \mathrm{ml} / \mathrm{kg}$ tidal volume and 6 or $8 \mathrm{cmH}_{2} \mathrm{O}$ of PEEP, the reports failed to clarify the mechanism underlying the observed change in arterial oxygenation during OLV, specifically as correlated with low tidal volumes and PEEP or with conventional tidal volume.

We hypothesize that a preemptive alveolar recruitment strategy before OLV attenuates the arterial oxygenation decrease during OLV. In the present study, we determined the effect of preemptive ARS on arterial oxygenation and pulmonary mechanics during OLV using either a low tidal volume (LTV) with PEEP or a high tidal volume (HTV) in patients with normal pulmonary function.

\section{Materials and Methods}

This study was approved by our Institutional Review Board and informed consent was obtained from all patients or guardians. Included patients underwent wedge resection by video assisted thoracostomy under general anesthesia in the right lung due to spontaneous pneumothorax. In total, 120 patients (age, 20-55 years) designated as American Society of Anesthesiologists class I or II were enrolled. Exclusion criteria were the presence of contralateral bullae, previous lung surgery, uncompensated cardiac disease, arrhythmia, other pulmonary disease, or other pleural disease causing a forced expiratory volume in 1 second/forced vital capacity $\left(\mathrm{FEV}_{1} / \mathrm{FVC}\right)$ below $80 \%$ preoperatively.

Patients were administered midazolam $0.05 \mathrm{mg} / \mathrm{kg}$ intramuscularly one hour prior to anesthetic induction. Upon entering the surgical suite, the non-invasive blood pressure, electrocardiogram, and peripheral oxygen saturation were monitored. A modified Allen's test was performed, and a catheter was inserted into the radial artery to continuously monitor blood pressure and arterial blood gas. Anesthesia was induced with propofol 3 $\mu \mathrm{g} / \mathrm{ml}$ and remifentanil $3 \mathrm{ng} / \mathrm{ml}$ by target-controlled infusion at target-effect site. The patients were administered rocuronium $0.6 \mathrm{mg} / \mathrm{kg}$, and a left-sided double-lumen endobronchial tube (Mallinckrodt Medical Ltd., Athlone, Ireland), sized 39 or $37 \mathrm{Fr}$ for male or female patients, respectively, was inserted; its location was confirmed using a fiber-optic bronchoscope. Anesthesia was maintained with propofol-remifentanil, and patients were supplemented with oxygen. The tidal volume was regulated at $10 \mathrm{ml} / \mathrm{kg}$ based on the predicted body weight [4]. All patients were ventilated using the Datex Aestiva/5 anesthetic machine (Datex-Ohmeda, GE healthcare, Madison, Wisconsin, USA) in a volume-controlled ventilation (VCV) mode. End-tidal carbon dioxide tension $\left(\mathrm{ETCO}_{2}\right)$ was continuously monitored, and the respiratory rate was adjusted to maintain $\mathrm{ETCO}_{2}$ between $35-40$ $\mathrm{mmHg}$.

After moving the patient into a lateral position, the endobronchial tube location was confirmed using a fiber-optic bronchoscope, followed by mechanical ventilation using a 0.5 fraction of inspired oxygen $\left(\mathrm{FiO}_{2}\right)$ for 15 minutes to stabilize clinical parameters. The baseline mean arterial pressure (MAP), heart rate $(\mathrm{HR})$, arterial blood oxygen tension $\left(\mathrm{PaO}_{2}\right)$, and partial pressure of arterial oxygen to fraction of inspired oxygen $\left(\mathrm{PaO}_{2} /\right.$ $\mathrm{FiO}_{2}$ ) ratio were then recorded. A spirometer $\left(\mathrm{S} / 5^{\mathrm{TM}}\right.$ Compact Airway Module, E-CaioV, GE Healthcare Finland Oy, Helsinki, Finland) was used to measure the baseline peak airway pressure (Paw peak), plateau airway pressure (Paw plat), and static compliance during two-lung ventilation. The 120 patients were randomly allocated into four groups using a random number table. Group $\mathrm{H}$ received OLV at a $10 \mathrm{ml} / \mathrm{kg}$ tidal volume $(\mathrm{n}=30)$, group H-ARS received OLV at a $10 \mathrm{ml} / \mathrm{kg}$ tidal volume after applying pre-emptive ARS during TLV $(n=30)$, group L received OLV at a $6 \mathrm{ml} / \mathrm{kg}$ tidal volume with a $8 \mathrm{cmH}_{2} \mathrm{O}$ PEEP $(\mathrm{n}=30)$, and group L-ARS received OLV at a $6 \mathrm{ml} / \mathrm{kg}$ tidal volume with a $8 \mathrm{cmH}_{2} \mathrm{O}$ PEEP after applying pre-emptive ARS during TLV $(\mathrm{n}=30)$ (Table 1). At the end of surgical draping, ARS was performed in a pressure-controlled ventilation (PCV) mode. The driving pressure (Paw plat-PEEP) was adjusted to maintain a tidal volume identical to the volume during VCV. After a $3 \mathrm{~min}$ equilibration, the driving pressure was maintained constantly, and the external PEEP was progressively increased in $5 \mathrm{cmH}_{2} \mathrm{O}$ each minute until reaching $15 \mathrm{cmH}_{2} \mathrm{O}$; the driving pressure 
Table 1. Schematic Protocol of This Study

\begin{tabular}{|c|c|c|}
\hline & Before OLV & After OLV \\
\hline Group H & Vt $10 \mathrm{ml} / \mathrm{kg}(\mathrm{VCV})$ & Vt 10 ml/kg (VCV) \\
\hline Group H-ARS & Vt $10 \mathrm{ml} / \mathrm{kg}(\mathrm{VCV}) \quad$ ARS (PCV) & Vt 10 ml/kg (VCV) \\
\hline Group L & Vt $10 \mathrm{ml} / \mathrm{kg}(\mathrm{VCV})$ & $\mathrm{Vt} 6 \mathrm{ml} / \mathrm{kg}+\mathrm{PEEP} 8 \mathrm{cmH}_{2} \mathrm{O}(\mathrm{VCV})$ \\
\hline Group L-ARS & $\mathrm{Vt} 10 \mathrm{ml} / \mathrm{kg}(\mathrm{VCV})$ & $\mathrm{Vt} 6 \mathrm{ml} / \mathrm{kg}+$ PEEP $8 \mathrm{cmH}_{2} \mathrm{O}(\mathrm{VCV})$ \\
\hline
\end{tabular}

Group $\mathrm{H}$ received OLV at a $10 \mathrm{ml} / \mathrm{kg}$ tidal volume $(\mathrm{n}=30)$, group $\mathrm{H}$-ARS received OLV at a $10 \mathrm{ml} / \mathrm{kg}$ tidal volume after applying pre-emptive ARS during TLV $(\mathrm{n}=30)$, group L received OLV at a $6 \mathrm{ml} / \mathrm{kg}$ tidal volume with a $8 \mathrm{cmH}_{2} \mathrm{O}$ PEEP $(\mathrm{n}=30)$, and group L-ARS received OLV at a $6 \mathrm{ml} / \mathrm{kg}$ tidal volume with a $8 \mathrm{cmH}_{2} \mathrm{O}$ PEEP after applying pre-emptive ARS during TLV $(\mathrm{n}=30)$. ARS was performed in a pressure-controlled ventilation (PCV) mode. After a 3 min equilibration, the external PEEP was progressively increased in $5 \mathrm{cmH}_{2} \mathrm{O}$ each minute until reaching $15 \mathrm{cmH}_{2} \mathrm{O}$; the driving pressure was then increased to a final Paw plat of $40 \mathrm{cmH}_{2} \mathrm{O}$. A $40 / 15$ recruitment pressure was applied for at least 10 breaths at a 10 breath/min respiratory rate until OLV began: volume controlled ventilation, OLV: one lung ventilation, PEEP: positive end-expiratory pressure, Vt: tidal volume.

Table 2. The Demographic Data, the Preoperative Data, and the Alveolar Recruitment Strategy Time

\begin{tabular}{|c|c|c|c|c|}
\hline & $\begin{array}{l}\text { Group H } \\
(\mathrm{n}=30)\end{array}$ & $\begin{array}{c}\text { Group H-ARS } \\
\quad(\mathrm{n}=30)\end{array}$ & $\begin{array}{l}\text { Group L } \\
(\mathrm{n}=30)\end{array}$ & $\begin{array}{l}\text { Group L-ARS } \\
\quad(\mathrm{n}=30)\end{array}$ \\
\hline Age (yr) & $36.3 \pm 9.5$ & $29.6 \pm 10.2$ & $35.2 \pm 10.2$ & $32.8 \pm 9.9$ \\
\hline Gender $(\mathrm{M} / \mathrm{F})$ & $27 / 3$ & $27 / 4$ & $27 / 3$ & $25 / 5$ \\
\hline Height $(\mathrm{cm})$ & $174.2 \pm 7.2$ & $174.5 \pm 6.5$ & $173.1 \pm 6.8$ & $172.8 \pm 7.7$ \\
\hline Weight (kg) & $61.5 \pm 5.8$ & $58.0 \pm 6.9$ & $61.2 \pm 8.5$ & $60.1 \pm 10.9$ \\
\hline Hemoglobin $(\mathrm{g} / \mathrm{dl})$ & $13.2 \pm 0.8$ & $13.2 \pm 0.6$ & $13.3 \pm 0.5$ & $13.5 \pm 0.6$ \\
\hline $\mathrm{PaO}_{2}(\mathrm{mmHg})$ & $94.65 \pm 2.63$ & $94.00 \pm 2.67$ & $94.50 \pm 3.35$ & $93.77 \pm 2.90$ \\
\hline $\mathrm{FVC}(\mathrm{L})$ & $3.07 \pm 0.24$ & $3.10 \pm 0.19$ & $3.15 \pm 0.17$ & $3.19 \pm 0.12$ \\
\hline $\mathrm{FEV}_{1}(\mathrm{~L})$ & $2.88 \pm 0.24$ & $2.85 \pm 0.18$ & $2.89 \pm 0.13$ & $2.95 \pm 0.16$ \\
\hline $\mathrm{FEV}_{1} / \mathrm{FVC}(\%)$ & $93.98 \pm 4.21$ & $92.19 \pm 3.09$ & $91.78 \pm 4.02$ & $92.35 \pm 3.10$ \\
\hline ARS time ( $\mathrm{min}$ ) & & $3.40 \pm 1.30$ & & $4.13 \pm 1.70$ \\
\hline
\end{tabular}

Values are expressed as mean $\pm \mathrm{SD}$ or a number of patients. There are no significant differences among groups. Group $\mathrm{H}$ received OLV at a $10 \mathrm{ml} / \mathrm{kg}$ tidal volume $(\mathrm{n}=30)$, group H-ARS received OLV at a $10 \mathrm{ml} / \mathrm{kg}$ tidal volume after applying pre-emptive ARS during TLV $(\mathrm{n}=30)$, group L received OLV at a $6 \mathrm{ml} / \mathrm{kg}$ tidal volume with a $8 \mathrm{cmH}_{2} \mathrm{O}$ PEEP $(\mathrm{n}=30)$, and group L-ARS received OLV at a $6 \mathrm{ml} / \mathrm{kg}$ tidal volume with a $8 \mathrm{cmH} \mathrm{O}_{2} \mathrm{PEEP}$ after applying pre-emptive ARS during TLV $(\mathrm{n}=30)$. ARS: alveolar recruitment strategy, Vt: tidal volume.

was then increased to a final Paw plat of $40 \mathrm{cmH}_{2} \mathrm{O}$. A $40 / 15$ recruitment pressure was applied for at least 10 breaths at a 10 breaths/min respiratory rate until OLV began [14,17]. ARS time was defined as the duration from applying a 40/15 recruitment pressure to starting OLV. OLV began by opening the proximal endobronchial tube within the non-dependent lung; then, the tidal volume and PEEP were delivered according to institutional protocols using VCV mode.

OLV was initiated at $1.0 \mathrm{FiO}_{2}$ at the first incision. Hemodynamic function, pulmonary function, and arterial blood gas were measured at 5 (T5), 15 (T15), 30 (T30), and $45 \mathrm{~min}$ (T45) after OLV. In addition, the static compliance immediately after ARS (T-ARS) was measured. Hypoxemia was defined as arterial hemoglobin oxygen saturation $\left(\mathrm{SaO}_{2}\right)$ below $90 \%$ after OLV. When hypoxemia developed, a standard procedure was performed to raise $\mathrm{SaO}_{2}$; these patients were excluded from the $\mathrm{PaO}_{2} / \mathrm{FiO}_{2}$ ratio and spirometery analyses.

Prior analysis showed that 112 patients were required to achieve a 0.25 effects size, $0.05 \alpha$, and $0.2 \beta$ values. A total 120 patients were recruited, and 30 were allocated to each group. All measurements are presented as mean \pm standard deviation.
The data were analysed using SPSS ver. 20.0 for Windows (SPSS, Inc., Chicago, IL, USA). The Chi-square test, Student's unpaired t-test, and one-way ANOVA were used to analyse demographic data and baseline values. Hemodynamic parameters (MAP and HR), spirometer parameters (Paw peak, Paw plat, and static compliance), and $\mathrm{PaO}_{2} / \mathrm{FiO}_{2}$ ratio were compared by repeated measures ANOVA and the Tukey HSD post-hoc test. One-way ANOVA followed by the Tukey HSD post-hoc test were used to compare the groups over time. Statistical significance was designated at $\mathrm{P}<0.05$.

\section{Results}

Demographic and preoperative data of the 120 enrolled patients were similar among the four groups (Table 2). The ARS time between H-ARS and L-ARS groups were not significantly different (Table 2).

The $\mathrm{PaO}_{2} / \mathrm{FiO}_{2}$ ratio was significantly reduced after initiating OLV in all groups compared to baseline, although this is not apparent in Fig. 1. The $\mathrm{PaO}_{2} / \mathrm{FiO}_{2}$ ratio of the $\mathrm{H}$-ARS group was higher during $\mathrm{T} 15$ to $\mathrm{T} 45$ than observed in the $\mathrm{H}$ group (360 


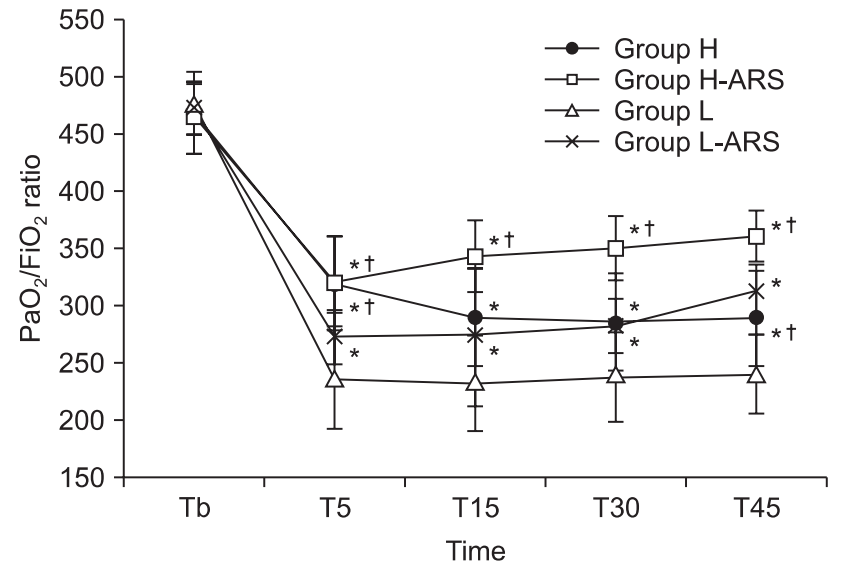

Fig. 1. The ratio of partial pressure of arterial oxygen and fraction of inspired oxygen $\left(\mathrm{PaO}_{2} / \mathrm{FiO}_{2}\right.$ ratio). Values are expressed as mean \pm SD. Group H received OLV at a $10 \mathrm{ml} / \mathrm{kg}$ tidal volume $(\mathrm{n}=30)$, group $\mathrm{H}$-ARS received OLV at a $10 \mathrm{ml} / \mathrm{kg}$ tidal volume after applying preemptive ARS during TLV $(\mathrm{n}=30)$, group $\mathrm{L}$ received OLV at a $6 \mathrm{ml} / \mathrm{kg}$ tidal volume with a $8 \mathrm{cmH}_{2} \mathrm{O}$ PEEP $(\mathrm{n}=30)$, and group L-ARS received OLV at a $6 \mathrm{ml} / \mathrm{kg}$ tidal volume with a $8 \mathrm{cmH}_{2} \mathrm{O}$ PEEP after applying pre-emptive ARS during TLV $(\mathrm{n}=30)$. Tb: During TLV Before starting ARS, T5: 5 min after OLV, T15: 15 min after OLV, T30: 30 min after OLV, T45: 45 min after OLV. ARS: alveolar recruitment strategy, Vt: tidal volume, OLV: one-lung ventilation. ${ }^{*} \mathrm{P}<0.05$ is compared with Group L, ${ }^{\dagger} \mathrm{P}<0.05$ is compared with Group L-ARS.
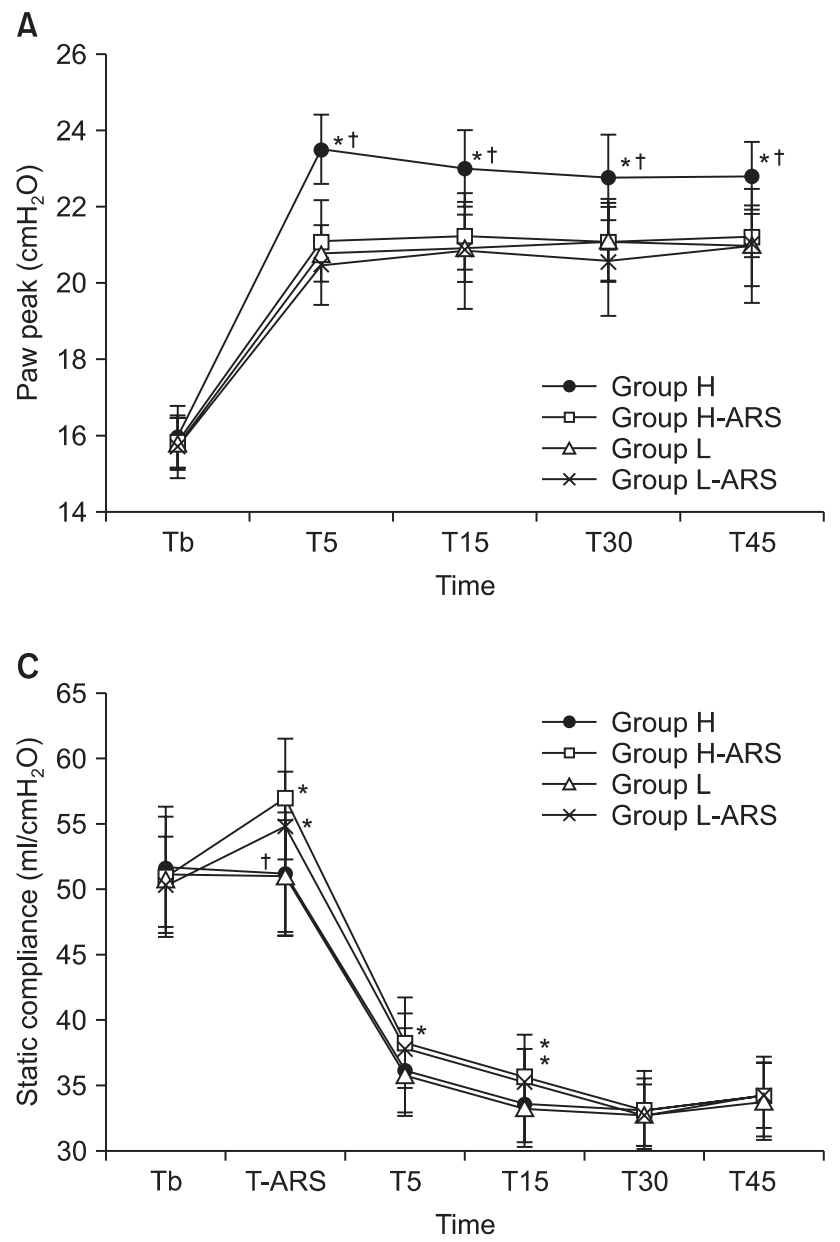

\pm 22 and $289 \pm 41 \mathrm{mmHg}$ at T45, respectively, $\mathrm{P}<0.05$, Fig. 1). $\mathrm{PaO}_{2} / \mathrm{FiO}_{2}$ ratios in the $\mathrm{L}(236 \pm 43 \mathrm{mmHg})$ and L-ARS $(272 \pm$ $24 \mathrm{mmHg}$ ) groups were significantly lower at $\mathrm{T} 5$ than in the $\mathrm{H}$ $(317 \pm 43 \mathrm{mmHg})$ and $\mathrm{H}$-ARS $(321 \pm 39 \mathrm{mmHg})$ groups $(\mathrm{P}<0.05$, Fig. 1). The $\mathrm{PaO}_{2} / \mathrm{FiO}_{2}$ ratios in the $\mathrm{L}$ and $\mathrm{L}-\mathrm{ARS}$ groups were significantly lower at all times than in the H-ARS group (240 \pm $35,312 \pm 24$, and $360 \pm 22 \mathrm{mmHg}$ at T45, respectively; $\mathrm{P}<0.05$, Fig. 1). The $\mathrm{PaO}_{2} / \mathrm{FiO}_{2}$ ratio in group L-ARS was similar to the ratio in group $\mathrm{H}$, but was significantly higher at T45 (312 \pm 24 vs. $289 \pm 41 \mathrm{mmHg}$, respectively, $\mathrm{P}<0.05$, Fig. 1$)$. There were no incidents of hypoxemia during OLV in any group.

Peak and plateau airway pressures were lowest in the L-ARS group. Group $\mathrm{H}\left(22.8 \pm 0.9 \mathrm{cmH}_{2} \mathrm{O}\right)$ had significantly higher peak airway pressure than Groups H-ARS, L, and L-ARS at T45 $\left(21.2 \pm 0.6,21.0 \pm 1.1\right.$, and $21.0 \pm 1.5 \mathrm{cmH}_{2} \mathrm{O}$, respectively; $\mathrm{P}<0.05$, Fig. 2A). The plateau airway pressure in groups $\mathrm{L}$ and L-ARS were significantly lower than in groups $\mathrm{H}$ and $\mathrm{H}$-ARS from $\mathrm{T} 5$ to T45 ( $\mathrm{P}<0.05$, Fig. 2B).

There were no significant differences in the static compliances between groups $\mathrm{H}$ and $\mathrm{L}$ or between groups $\mathrm{H}$-ARS and L-ARS. However, the static compliance in the ARS groups were

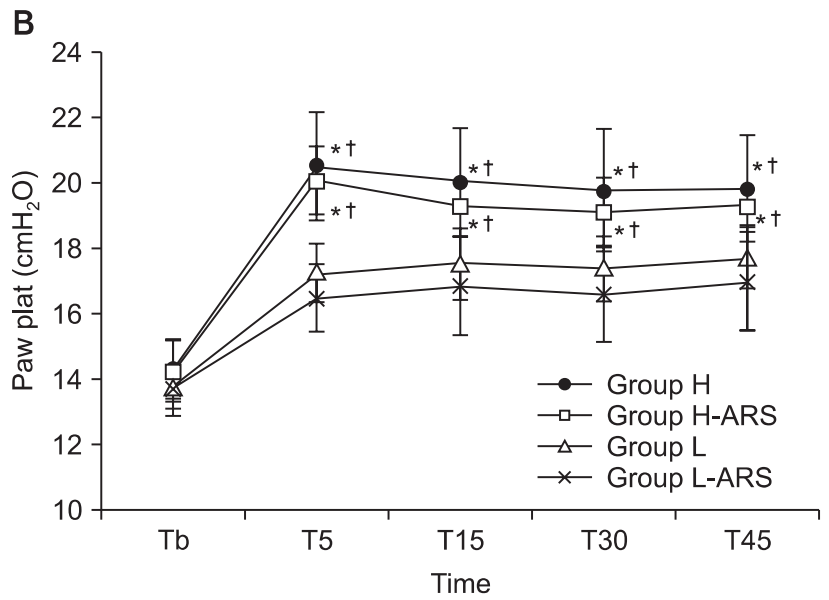

Fig. 2. The changes of the peak airway pressure (A), the plateau airway pressure (B), and the static compliance $(\mathrm{C})$. Values are expressed as mean $\pm \mathrm{SD}$. Group $\mathrm{H}$ received OLV at a $10 \mathrm{ml} / \mathrm{kg}$ tidal volume $(\mathrm{n}=30)$, group $\mathrm{H}$-ARS received OLV at a $10 \mathrm{ml} / \mathrm{kg}$ tidal volume after applying preemptive ARS during TLV $(\mathrm{n}=30)$, group L received OLV at a $6 \mathrm{ml} / \mathrm{kg}$ tidal volume with a $8 \mathrm{cmH}_{2} \mathrm{O}$ PEEP $(\mathrm{n}=30)$, and group L-ARS received OLV at a $6 \mathrm{ml} / \mathrm{kg}$ tidal volume with a $8 \mathrm{cmH}_{2} \mathrm{O}$ PEEP after applying pre-emptive ARS during TLV $(\mathrm{n}=30)$. Tb: During TLV Before starting ARS, T-ARS: Just before OLV with or without ARS, T5: 5 min after OLV, T15: 15 min after OLV, T30: $30 \mathrm{~min}$ after OLV, T45: $45 \mathrm{~min}$ after OLV. ARS: alveolar recruitment strategy, Vt: tidal volume, OLV: one-lung ventilation. ${ }^{*} \mathrm{P}<0.05$ is compared with Group $\mathrm{L},{ }^{\dagger} \mathrm{P}<0.05$ is compared with Group L-ARS. 
significantly higher than in the $\mathrm{H}$ and $\mathrm{L}$ groups from the end of ARS to T15, except at T5 even though there were non-significant differences in group L compared with group L-ARS at T5 $\left(35.7 \pm 3.2,35.2 \pm 2.6,33.6 \pm 3.0\right.$, and $33.2 \pm 2.9 \mathrm{ml} / \mathrm{cmH}_{2} \mathrm{O}$ at T15, respectively, group H-ARS, L-ARS, H, and L, P < 0.05, Fig. 2C).

MAP and HR values were similar among the groups.

\section{Discussion}

This study showed that preemptive ARS improves arterial oxygenation $\left(\mathrm{PaO}_{2} / \mathrm{FiO}_{2}\right.$ ratio $)$ at varying tidal volumes both with and without PEEP without significantly changing hemodynamic function. Although the $\mathrm{H}$-ARS group had the highest $\mathrm{PaO}_{2} /$ $\mathrm{FiO}_{2}$ ratio during OLV, the L-ARS group showed an improved arterial oxygenation similar to that of the $\mathrm{H}$ group, which was significantly higher than in group L. The preemptive ARS was associated with a significantly increased static compliance for 30 minutes after initiating OLV. Furthermore, while peak airway pressure in group H-ARS showed no significant difference compared to group L-ARS, the plateau airway pressure in group $\mathrm{H}$-ARS was significantly higher than in group L-ARS.

During general anesthesia with TLV, ARS has been shown to effectively improve arterial oxygenation without cardiopulmonary or vascular complications $[17,18]$. The impact of ARS on arterial oxygenation has also been studied in patients undergoing thoracic surgery with OLV [13-16]. Potentially, hypoxemia during OLV may be induced by atelectasis, which causes a ventilation/perfusion mismatch and a right-to-left shunt [19]; this OLV-induced atelectasis could be reversed or prevented using ARS, which is generally used to improve oxygenation under conditions that produce hypoxemia $[20,21]$. In a study by Tusman et al. [15], ARS was performed by increasing PIP to 40 $\mathrm{cmH}_{2} \mathrm{O}$ at a PEEP of $20 \mathrm{cmH}_{2} \mathrm{O}$ for 10 respiratory cycles in the dependent lung after starting OLV. As a result, the $\mathrm{PaO}_{2}(470$ $\mathrm{mmHg}$ ) improved compared to OLV without alveolar recruitment (217 mmHg), which was similar to $\mathrm{PaO}_{2}$ during TLV (515 $\mathrm{mmHg}$ ). In another study by Tusman et al. [16], ARS improved arterial oxygenation by decreasing the dead space and increasing the efficiency of ventilation and $\mathrm{CO}_{2}$ exchange. Park et al. [13] similarly performed pre-emptive ARS at 10 manual breaths with a $40 \mathrm{cmH}_{2} \mathrm{O}$ PIP followed by a $15 \mathrm{cmH}_{2} \mathrm{O}$ PEEP during TLV before starting OLV. They found that preemptive ARS effectively improved arterial oxygenation during the entire OLV period using a $6 \mathrm{ml} / \mathrm{kg}$ tidal volume and a $5 \mathrm{cmH}_{2} \mathrm{O}$ PEEP; the $\mathrm{PaO}_{2}$ improved approximately $25 \%$ before the air leakage test. Unzueta et al. [14] suggested that ARS at a $40 \mathrm{mmHg}$ plateau pressure, $20 \mathrm{cmH}_{2} \mathrm{O} \mathrm{PEEP}$, and $6 \mathrm{ml} / \mathrm{kg}$ tidal volume performed immediately before OLV decreased the alveolar component of dead space, which subsequently reversed the lung collapse and shunt. Overall, arterial oxygenation improved approximately
$27 \%$, which was sustained through the entire surgical procedure. In the present study, preemptive ARS significantly improved arterial oxygenation and static compliance, without significantly changing hemodynamics during OLV. Although we did not measure the atelectic area, our results are consistent with those in a study by Rothen et al. [22], which found that the mean atelectic area decreased to $0.1 \mathrm{~cm}^{2}$ immediately after applying ARS, then slowly increased to $1.9 \mathrm{~cm}^{2}$ after $40 \mathrm{~min}$. Reportedly, a PIP of at least $40 \mathrm{cmH}_{2} \mathrm{O}$ is required to fully reverse atelectasis during general anesthesia [22]. Lachmann et al. [23] found that the combination of a $40 \mathrm{cmH}_{2} \mathrm{O}$ PIP and sufficient PEEP will keep the recruited alveoli open, which reduces atelectasis and improves lung compliance. However, the optimal PEEP remains controversial and difficult to predict. Therefore, our ARS protocol comprised $40 \mathrm{cmH}_{2} \mathrm{O}$ plateau pressure to reverse the general anesthesia-induced atelectasis and a $15 \mathrm{cmH}_{2} \mathrm{O}$ PEEP to keep the alveoli open $[13,14,17]$.

Numerous studies show a decreasing trend in Paw plat and Paw peak after ARS, as well as an increased compliance after successful alveolar recruitment $[10,13,24,25]$. In an animal study, dynamic lung compliance increased during mechanical ventilation at a $10 \mathrm{ml} / \mathrm{kg}$ tidal volume after the recruitment maneuver; this effect was maintained for 60 minutes [25]. In contrast, Hedenstierna and Tenling [10] did not observe any significant differences in Paw plat and Paw peak after ARS performed at a $40 \mathrm{cmH}_{2} \mathrm{O}$ PIP and a $20 \mathrm{cmH}_{2} \mathrm{O}$ PEEP during OLV at a $8 \mathrm{ml} / \mathrm{kg}$ tidal volume and a $5 \mathrm{cmH}_{2} \mathrm{O}$ PEEP. They did observed a significant decrease in the statistic respiratory elastance. In the present study, despite the significant increment change in Paw peak in the H-ARS group, Paw plat, Paw peak, and static compliance did significantly change in the LTV groups during and after ARS. Furthermore, the improved static compliance was maintained for 30 minutes after performing pre-emptive ARS.

The majority of studies assessing oxygenation during OLV use low tidal volume ventilation, based on the rationale that pulmonary injury may be induced by ventilation performed at the TLV tidal volume. However, the optimal tidal volume required to maintain or improve arterial oxygenation during OLV has not been determined. A tidal volume of $10-12 \mathrm{ml} / \mathrm{kg}$ was recommended to prevent atelectasis during OLV, which can occurs below a $8 \mathrm{ml} / \mathrm{kg}$ tidal volume, based on the clinical finding that high tidal volume during OLV can improve oxygenation $[5,26]$. Several studies suggest that the conventional tidal volume used for TLV during OLV may cause pulmonary injury by increasing the peak and plateau airway pressures [27], and these studies recommended a lower tidal volume and sufficient PEEP to prevent or attenuate pulmonary injury and prevent hypoxemia [6-9]. However, the optimal PEEP required maintaining oxygenation during low tidal OLV is unknown. In a previous study, we showed that $5 \mathrm{cmH}_{2} \mathrm{O}$ PEEP combined with a $6 \mathrm{ml} / \mathrm{kg}$ tidal 
volume during OLV did not improve arterial oxygenation compared to oxygenation during a 6 or $10 \mathrm{ml} / \mathrm{kg}$ tidal volume alone [26]. The present study also shows that $8 \mathrm{cmH}_{2} \mathrm{O}$ PEEP with 6 $\mathrm{ml} / \mathrm{kg}$ tidal volume did not maintain arterial oxygenation as robustly as the $10 \mathrm{ml} / \mathrm{kg}$ tidal volume alone. Unfortunately, we did not measure the delivered tidal volume or assess PEEP induced lung injury. Notably, a previous study recommended keeping the plateau and peak airway pressures below $25 \mathrm{cmH}_{2} \mathrm{O}$ and 35 $\mathrm{cmH}_{2} \mathrm{O}$, respectively, to reduce the risk of lung injury [8]. In the present study, these pressures were below the recommended thresholds during OLV, and we did not observe any evidence of significant lung injury on postoperative chest radiographs.

The present study has several limitations. We did not accommodate the effect of intrinsic PEEP (PEEPi) that might appear during OLV. Although no PEEPi does not occur during TLV, but a 2-6 $\mathrm{cmH}_{2} \mathrm{O}$ PEEPi can appear during OLV [28], and this range can modulate the effect of externally applied PEEP. To improve arterial oxygenation, PEEPi should be measured individually, and an external PEEP should be applied equal in magnitude to PEEPi. However, external PEEP should not be increased greater than $5 \mathrm{mmHg}$ above PEEPi as this eliminates the improved pulmonary gas exchange and reduces cardiac output [28]. Certain anesthesia machines may also cause a $2-4 \mathrm{cmH}_{2} \mathrm{O}$ PEEPi, though this is usually ignored by anesthesiologists. Unfortunately, our study as well as most others did not accommodate the measured PEEPi when applying the optimal external
PEEP. We observed that the plateau pressure remained stable during OLV with LTV and external PEEP, and no evidence of dynamic hyperinflation caused by PEEPi was observed. This can be partially attributed to our exclusion of patients with obstructive disease and obstructive pulmonary function because there is an inverse correlation between the preoperative percentages of predicted $\mathrm{FEV}_{1}$ and $\mathrm{PaO}_{2}$ during OLV [5]. In addition, we only enrolled patients with normal preoperative pulmonary function. Therefore, this study does not indicate the safety of preemptive ARS in the patients with other pulmonary diseases.

In summary, this study showed that preemptive ARS effectively improved arterial oxygenation during one-lung ventilation irrespective of tidal volume. Although the $\mathrm{PaO}_{2} / \mathrm{FiO}_{2}$ ratio was higher in group $\mathrm{H}(\mathrm{Vt} 10 \mathrm{ml} / \mathrm{kg}$ ) than in group L (Vt $6 \mathrm{ml} /$ $\mathrm{kg}$ with a $8 \mathrm{cmH}_{2} \mathrm{O} \mathrm{PEEP}$ ), the $\mathrm{PaO}_{2} / \mathrm{FiO}_{2}$ ratio in group $\mathrm{H}$ was similar to that in group L-ARS, except at $5 \mathrm{~min}$ after OLV. Therefore, we conclude that applying a $6 \mathrm{ml} / \mathrm{kg}$ tidal volume with a $8 \mathrm{cmH}_{2} \mathrm{O}$ PEEP after preemptive ARS may reduce the risk of pulmonary injury caused by high tidal volume during one-lung ventilation in patients with normal pulmonary function.

\section{Acknowledgments}

This study was supported by research funds from Chosun University, 2010.

\section{References}

1. Karzai W, Schwarzkopf K. Hypoxemia during one-lung ventilation: prediction, prevention, and treatment. Anesthesiology 2009; 110: 140211.

2. Hurford WE, Alfille PH. A quality improvement study of the placement and complications of double-lumen endobronchial tubes. J Cardiothorac Vasc Anesth 1993; 7: 517-20.

3. Schwarzkopf K, Klein U, Schreiber T, Preussetaler NP, Bloos F, Helfritsch H, et al. Oxygenation during one-lung ventilation: the effects of inhaled nitric oxide and increasing levels of inspired fraction of oxygen. Anesth Analg 2001; 92: 842-7.

4. Gal TJ. Con: low tidal volumes are indicated during one-lung ventilation. Anesth Analg 2006; 103: 271-3.

5. Katz JA, Laverne RG, Fairley HB, Thomas AN. Pulmonary oxygen exchange during endobronchial anesthesia: effect of tidal volume and PEEP. Anesthesiology 1982; 56: 164-71.

6. Végh T, Juhász M, Szatmári S, Enyedi A, Sessler DI, Szegedi LL, et al. Effects of different tidal volumes for one-lung ventilation on oxygenation with open chest condition and surgical manipulation: a randomised cross-over trial. Minerva Anestesiol 2013; 79: 24-32.

7. Licker M, Fauconnet P, Villiger Y, Tschopp JM. Acute lung injury and outcomes after thoracic surgery. Curr Opin Anaesthesiol 2009; $22: 61-7$.

8. Slinger P. Pro: low tidal volume is indicated during one-lung ventilation. Anesth Analg 2006; 103: 268-70.

9. Hoftman N, Canales C, Leduc M, Mahajan A. Positive end expiratory pressure during one-lung ventilation: selecting ideal patients and ventilator settings with the aim of improving arterial oxygenation. Ann Card Anaesth 2011; 14: 183-7.

10. Cinnella G, Grasso S, Natale C, Sollitto F, Cacciapaglia M, Angiolillo M, et al. Physiological effects of a lung-recruiting strategy applied during one-lung ventilation. Acta Anaesthesiol Scand 2008; 52: 766-75.

11. Hedenstierna G, Tenling A. The lung during and after thoracic anaesthesia. Curr Opin Anaesthesiol 2005; 18: $23-8$.

12. Fortier G, Coté D, Bergeron C, Bussières JS. New landmarks improve the positioning of the left Broncho-Cath double-lumen tubecomparison with the classic technique. Can J Anaesth 2001; 48: 790-4.

13. Park SH, Jeon YT, Hwang JW, Do SH, Kim JH, Park HP. A preemptive alveolar recruitment strategy before one-lung ventilation improves arterial oxygenation in patients undergoing thoracic surgery: a prospective randomised study. Eur J Anaesthesiol 2011; 28: 298-302. 
14. Unzueta C, Tusman G, Suarez-Sipmann F, Böhm S, Moral V. Alveolar recruitment improves ventilation during thoracic surgery: a randomized controlled trial. Br J Anaesth 2012; 108: 517-24.

15. Tusman G, Böhm SH, Melkun F, Staltari D, Quinzio C, Nador C, et al. Alveolar recruitment strategy increases arterial oxygenation during one-lung ventilation. Ann Thorac Surg 2002; 73: 1204-9.

16. Tusman G, Bohm SH, Sipmann FS, Maisch S. Lung recruitment improves the efficiency of ventilation and gas exchange during one-lung ventilation anesthesia. Anesth Analg 2004; 98: 1604-9.

17. Park HP, Hwang JW, Kim YB, Jeon YT, Park SH, Yun MJ, et al. Effect of pre-emptive alveolar recruitment strategy before pneumoperitoneum on arterial oxygenation during laparoscopic hysterectomy. Anaesth Intensive Care 2009; 37: 593-7.

18. Pang CK, Yap J, Chen PP. The effect of an alveolar recruitment strategy on oxygenation during laparascopic cholecystectomy. Anaesth Intensive Care 2003; 31: 176-80.

19. Dunn PF. Physiology of the lateral decubitus position and one-lung ventilation. Int Anesthesiol Clin 2000; 38: 25-53.

20. Lapinsky SE, Mehta S. Bench-to-bedside review: Recruitment and recruiting maneuvers. Crit Care 2005; 9: 60-5.

21. Maggiore SM, Lellouche F, Pigeot J, Taille S, Deye N, Durrmeyer X, et al. Prevention of endotracheal suctioning-induced alveolar derecruitment in acute lung injury. Am J Respir Crit Care Med 2003; 167: 1215-24.

22. Rothen HU, Sporre B, Engberg G, Wegenius G, Hedenstierna G. Reexpansion of atelectasis during general anaesthesia may have a prolonged effect. Acta Anaesthesiol Scand 1995; 39: 118-25.

23. Lachmann B. Open up the lung and keep the lung open. Intensive Care Med 1992; 18: 319-21.

24. Kozian A, Schilling T, Schütze H, Senturk M, Hachenberg T, Hedenstierna G. Ventilatory protective strategies during thoracic surgery: effects of alveolar recruitment maneuver and low-tidal volume ventilation on lung density distribution. Anesthesiology 2011; 114: 1025-35.

25. Klingstedt C, Hedenstierna G, Lundquist H, Strandberg A, Tokics L, Brismar B. The influence of body position and differential ventilation on lung dimensions and atelectasis formation in anaesthetized man. Acta Anaesthesiol Scand 1990; 34: 315-22.

26. Kim SH, Jung KT, An TH. Effects of tidal volume and PEEP on arterial blood gases and pulmonary mechanics during one-lung ventilation. J Anesth 2012; 26: 568-73.

27. Szegedi LL, Bardoczky GI, Engelman EE, d'Hollander AA. Airway pressure changes during one-lung ventilation. Anesth Analg 1997; 84: 1034-7.

28. Inomata S, Nishikawa T, Saito S, Kihara S. "Best" PEEP during one-lung ventilation. Br J Anaesth 1997; 78: 754-6. 